\title{
البنية العاملية للمناخ المدرسي للدى طلاب المرحلة الثانوية
}

\author{
إعداد
}

أ زهلة أحمد محمد شبيب

$$
\text { باحثة ماجستير - قسم علم النفس التربوي }
$$


البنية العاملية للمناخ المدرسي لاثى طلاب المرحلة الثانوية

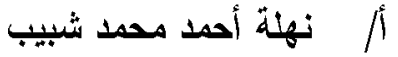

\section{البنية العاملية للمناخ الملدربي للدى طلاب المرحلة الثانوية}

\section{إعداد}

\section{أ/ نهلة أحمد محمد شبيب}

باحثة ماجستير - قسم علم النفس التزبوى

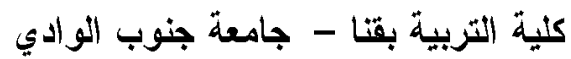

:

هدفت الدراسة الى التعرف على البناء العاملى لمقياس المناخ المدرسى لدى طلاب المرحلة الثانوية ، وقد تكونت عينة البحث من .ب طالب وطالبة

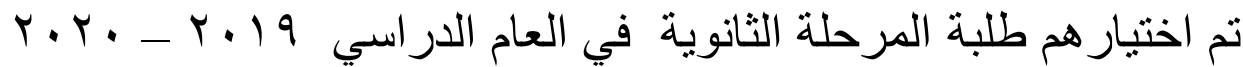
م ، وقد نوصلت نتائج الدراسة الى تحديد مفهوم المناخ المدرسي على النحو الآتي ، وجود مجموعة من المعايير والقيم التي تدعم شعور الطلاب نفسيا واجتماعيا وامنيا كنتاج للعلاقات الثخصية بين الطلبة واولياء الامور و المعلمين من خلال رؤية مشتركة للاحتر ام والالتز ام

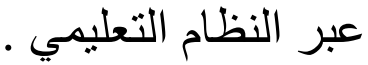
الكلمات المفتاحية : البناء العاملى ، المناخ المدرسى . 


\title{
The Factorial Structure of the school climate for secondary school students
}

\author{
Prepare \\ Nahla Ahmed Mohamed Shabib \\ MA Researcher - Department of Educational Psychology \\ Faculty of Education in Qena - South Valley University
}

\begin{abstract}
:
The study aimed to identify the Factorial Structure of the school climate scale among high school students, and the research sample consisted of 200 students who were selected as secondary school students in the 20192020 academic year. A set of standards and values that support students' feelings of psychological, social and security as a product of personal relationships between students, parents and teachers through a shared vision of respect and commitment across the educational system .
\end{abstract} Keywords : Factorial Structure, school climate 
يحدد الباحثون المناخ المدرسي من وجهات نظر مختلفة ؛ على سبيل المثال ، حدد (\& Johnson,1993Johnson) المناخ المدرسي بأوسع معانيه حيث أن "المناخ المدرسي قد يثمل أي شيء من الجوانب البيئية للمدرسة إلى شخصيات الطلاب و المعلمين وكذلك الأداء الأكاديمي ومستويات النشاط البدني ، و العمليات والمواد المستخدمة خلال الإجر اءات التعليمية. ومع ذلك ، فمن الصعب الحصول على مدارس تفي بكل هذه الثروط في السياق.

في واقع الأمر تختلف البيئة المدرسية بشكل كبير من منظمة إلى أخرى. على الرغم من أن بعض المدارس تشعر بالود والجاذبية والدعم ، إلا أن البعض الآخر يشعر بالحرج و عدم الترحيب و عدم الآمان .و يثشار إلى المشاعر و المو اقف التي تقدمها بيئة المدرسة بالمناخ المدرسي. و على الرغم من صعوبة تقديم تعريف للمناخ المدرسي يتفق معظم الباحثين على أنه بناء متعدد الأبعاد بتضمن أبعادًا مادية واجتماعية و أكاديمية. ، وتم تحديد أبعاد

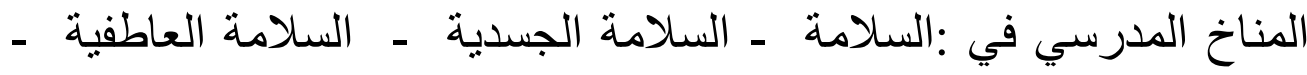
النظام وسلامة الانضباط ـ المناخ الأكاديمي - القيادة - التعليم و التعلم التطوير المهني ـ العلاقات ـ احترام التتوع والثر اكة المجتمعية ـالبيئة

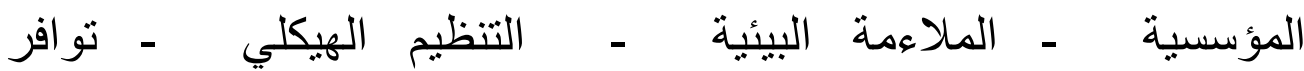
(Freiberg \& Stein,1999).ارود 
البنية العاملية للمناخ المدرسي لاثى طلاب المرحلة الثانوية

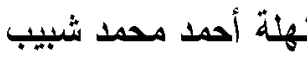

ان ابعاد المناخ المدرسي(Yueming et al.,2009) وقد اكدت نتائج

در اسة دعم الطالبــ دعم المعلم-فرص الحكم الذاتي في الفصول الدراسية ـ التوفق الاكاديمي لدى المر اهقين.علاوة على ذلك ، يصف المناخ المدرسي جودة مدرسة معينة عبارة عن مكان تعليمي صحي ؛ يلبى تطلعات الأطفال والآباء ؛ يلهم الإبداع والحماس لديهم ، ويشجع اعلى ممارسات التدريس و التعلم و الخبر ات و التفاعلات بين اعضاء المدرسة وخارج مجتمع المدرسة ،علاوة على ذلك ، يتعلق المناخ المدرسي بقيمة الحياة المدرسية وجودتها. وبالتالي ، يمكن للمدرسة التي تلبي احتياجات المناخ المدرسي أن تحدث فرقًا وبالتالي يمكن أن يكون لها نتائج أفضل.

(Cohen McCabe ‘Michelli ‘\& Pickeral ‘2009)

من ناحية أخرى أوضح (Kopperud\& Pomerantz 2012)

أن مناخ المدرسة هو مصطلح بعيد المدى يصف عادة مجمو عة متنو عة من الأبعاد التي تميز "روح" المدرسة. تنتوع العناصر التي تشمل مناخ المدرسة ، بدءًا من جودة تفاعلات المعلم والطالب إلى خصائص الهيكل المادي و التظظيمي للمدرسة ، فضلاً عن السلامة المتصورة وممارسات التدريس و التعلم. علاوة على ذلك ، فقد تم التأكيد على أن المناخ المدرسي هو التفاعلات الثخصية بين المجتمع المدرسي التي تؤثر إيجابًا أو سلبًا على التطور المعرفي والاجتماعي والنفسي للطلاب(Haynes et al.,1996) • يمكن أيضًا وصف مناخ المدرسة بأنه بناء معقد يُعنرف به كمتغير مهم للمدارس الفعالة. إنها قلب وروح المدرسة. يتعلق الأمر بجوهر المدرسة 
البنية العاملية للمناخ المدرسي لاثى طلاب المرحلة الثانوية

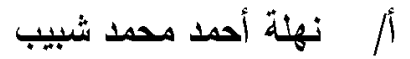

الذي يقود الطفل أو المعلم أو المسؤول أو الموظف إلى حب حب المدرسة

و التطلع إلى التو اجد هنالك كل يوم دراسي. يدور مناخ المدرسة حول نوعية المدرسة التي تساعد كل فرد على الثعور بالقيمة الثخصية والكرامة و الأهمية ، بينما نساعد في الوقت نفسه في خلق شعور بالانتماء إلى شيء

\section{يتجاوز أنفسنا(Freiberg \& Stein,1999).}

بثكل عام من المهم ملاحظة أنه "لا يوجد عامل و احد يحدد مناخ المدرسة". ومع ذلك فإن التفاعل بين العديد من قضايا المدرسة والفصول الدراسية يمكن أن ينتج نسيجًا من الدعم الذي يسمح أو يمكّن جميع أعضاء المجتمع المدرسي من التدريس و التعلم على أفضل المستويات(Freiberg,1998) . على الرغم من أن الباحثين المختلفين يعرّفون المناخ المدرسي من وجهات نظر مختلفة إلا أن الباحث يأخذ في الاعتبار ويشير إلى التعريف الذي يركز على زمالة المدير ، ومهنية المعلمين ، و الصحافة الأكاديمية (إلى أي مدى تكون المدرسة مدفو عة بالسعي إلى التميز و مشاركة المجتمع لمدرسة معينة ـ .يمكن اعتبار المناخ المدرسي مكان اجتماعي على الرغم من وجود اختلافات طفيفة ، إلا أن المدارس حول العالم متشنابهة بشكل ملحوظ. تختلف الهياكل التتظيمية للتعليم قليلاً فقط من بلد إلى آخر. أي مدرسة بغض النظر عن جودة وتوافر منشآتها أو مواردها ، على الأقل يجب أن يكون لديها مجموعة من الطلاب مع مدرس واحد ، و وأوقات محددة للتدريس ، و أوقات محددة لبدء اليوم الدراسي وإيقافه ، و الهياكل الإدارية التي تكون في الغالب هرمية. يتم فحص الطلاب من خلال اختبار المعلم الذي يتم إجراؤه في 
البلدان ، علاوة على ذللك ، مشاكل التعليم أيضا عالمية: ملل الطلاب كماب محئ يتضح من قلة الحضور (التغيب عن المدرسة) ؛ ترك المدرسة قبل بلوغ السن المحددة (التسرب) استخدام المنشطات التي تقلل من المشاركة (المخدر ات وشرب الكحول وتعاطي التبغ) (Freiberg \& Stein, 1999). اقترح الباحثون أنه يمكن تحسين المناخ المدرسي بالتركيز على أربعة ابعاد رئيسية. هي: الأمان ، و العلاقات التعليم و التعلم ، و البيئة الخارجية تعمل أشارت مجمو عة مثز ايدة من الأبحاث إلى (Dary \&Pickeral,2013) على تحسين المناخ المدرسي ، وبالتالي النتيجة هو الثخل الثـاغل للدول في العالم اليوم. لإجراء البحوث حول كيفية تحسين مناخ المدرسة على نقاط القوة من خلال الاستفسار التقديري لتأكيد ذلك ، ما إذا كان الاستفسار التقديري مرتبطًا بقياس التغيرات في مناخ المدرسة والثقة داخل المدرسة. ومن خلال هذه العملية تم تحديد ثلاثة مجالات للتحقيق ؛ وهي: إنجاز الطالب ونجاحه ، و الثقة و الاحتر ام ، و اعتز از المجتمع و انخر اطه.

ادرك العديد من الخبراء أهمية مجال و أبعاد المناخ المدرسي. أدى تطوير وتصميم الأدوات القائمة على أساس علمي لتقييم مناخ المدرسة إلى خلق أرضية غنية من الاهتمام البحثي حتى يومنا هذا. يمكن تعريف العبارة المشار إلبها على أنها شخصية أو حالة الحياة المدرسية التي تستند عادةً إلى أنماط تجارب حياة الطالب داخل الحرم المدرسي. كانت الحالة المذكورة نتيجة وتأثير ات القيم الطبيعية و السلوكيات و أهداف التعلم و عمليات التدريس و التعلم و التعهدات و التفاعلات الثخصية والاجتماعية و إدارة المدرسة 
والقيادة والتجارب الأخرى ونمط الحياة في الحياة اليومية. طالب في مئي المؤسسة. مع نضوج الدراسات من مفهومها ، تم اعتبار المناخ المدرسي عنصرًا ضروريًا ليكون مستدامًا ويعكس التأثيرات الإيجابية من أجل تعزيز وتعزيز التنمية البشرية الكلية للطلاب اللازمين لمجتمع منتج وتنافسي عالميا تشير أبحاث المناخ المدرسي الإيجابي ان العلاقات الثخصية وفرص التعلم المثلى للطلاب بشكل بوجه عام ابعاد للمناخ المدرسي وعلى ذلك يمكن للبيئات المدرسية زيادة مستويات الإنجاز وتقليل سوء التوافق McEvoy)

.\& Welker, 2000)

وجد (Taylor \&Tashakkori,1995) أن المناخ المدرسي الإيجابي يرتبط ببعد الرضا الوظيفي للعاملين بالمدرسة. وأخيرًا وجهات نظر الطالب مهم أثناء الانتقال من مستوى مدرسي إلى آخر والالتحاق بمدرسة جديدة ويمكن أن يكون مخيفًا للطلاب ويمكن أن يؤثر هذا التخوف سلبًا على بلى الطلاب وتصور ات لمناخ مدرستهم ونتائج التعلم

ويعد تحديد مفهوم المناخ المدرسي وثقافته عملية معقدة. استنادًا إلى حقيقة أنه لا يوجد تعريف عالمي للمناخ المدرسي. الباحثون استعرضوا الخصائص المختلفة التي تحدد بشكل فريد مناخ مدرسة على أخرى نظرًا لأن المدارس لديها قيم تتظيمية وثقافية وفردية مختلفة ، فإن الباحثين لديهم أكد على استخدام المجموعات الفرعية لتقييم العوامل المختلفة للمناخ المدرسي. 
(اقترح أن بعدا واحدًا من ابعاد المناخ المدرسي يمكن أن يكون قويًا للمضي قدمً لتحسين التوافق والاداء المدرسي نظرًا لأن أحد الحد

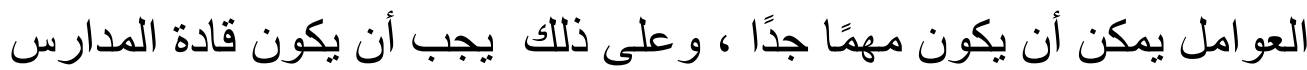
قادرين على تحديده.

حدد باحثون آخرون ودرسوا أربعة ابعاد رئيسية تشكل مناخ المدرسة السلامة والعلاقات و التعليم والتعلم والبيئة المؤسية (المدرسة الوطنية

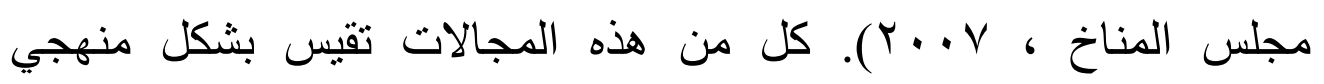
المجموعات الفرعية الفردية التي تشكل اتساق المناخ العام للمدرسة المركز الاجتماعي و العاطفي، و هناكمؤشرات لكل من لكل من البعدين الآتيين : أو لا : السلامة يمكن تحديد المدرسة من خلال القواعد و الأعر اف والسلامة الجسدية و الاجتماعية و العاطفية

ثانيا : الامان ينقسم التعليم و التعلم إلى مجمو عتين فرعيتين ، دعم التعلم و التعلم الاجتماعي و المدني. يتم تحديد المجموعة الفرعية الثالثة ، العلاقات الثخصية ، بواسطة احترام المدرسة للتنوع والدعم ال اجتماعي للكبار

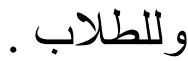

وقد أدى الاهتمام هذا بدراسة مفهوم المناخ المدرسي إلى ظهور مقاييس عدة تقبس هذا المفهوم ، كما تم دراسته في ظل العديد من المتغيرات بافتر اض أنه يختلف باختلافها مثل الجنس، ، و القيادة، و الثخصية، ونوعية العلاقات الاجتماعية، والرضا عن الحياة، والتحصيل الأكاديمي والمعلم. ومع ذللك فإن الإشكالية عند قياس المناخ الددرسي كانت تكمن في كيفية 
البنية العاملية للمناخ المدرسي لاثى طلاب المرحلة الثانوية

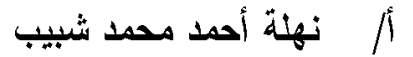

القياس في ظل هذه المتغيرات هل يمكن قياسه كعامل واحد أو متعدد العو امل. لذللك نشطت الأبحاث في هذا الجانب.

لذا فقد أدى ذللك الاهتمام إلى استثارة الباحثة للقيام بهذا البحث كمحاولة للتعرف على البناء العاملي لمفهوم المناخ المدرسي لدى عينة الدراسة المختارة و التي يمثل أفر ادها طلاب المرحلة الثانوية. وأن أهم مهمة للمناخ المدرسي كبيئة نفسية واجتماعية واكاديمية التثقيف و إكساب المتعلمين السلوكيات المرغوبة ، و التنمية الثخصية والاجتماعية. ويكونون قادرين على مساعدة أنفسهم لمو اجهة مشاكلهم الانفعالية، أو تكون لديهم القدرة على التعامل مع الآخرين. كما أن المعلمين الجيدين يدركون مهمتهم للمشاركة في عملية التعلم لأنها تكثف قدرة ملحوظة للحفاظ على نشاط الطلاب المشاركين في أداء المهام الدر اسية و إنجاز ها بكفاءة، كما أنه يمكنهم من أخذ أدوار أكثر نشاطاً في تشكيل حياتهم الاكاديمية .

من هذا المنطلق فإن ذلك يجعل الاهتمام متزايداً لمعرفة البناء العاملي لاستجاباتهم على مقياس المناخ المدرسي.

\section{مشكلة البحث}

تحددت مشكلة البحث في الآتي

ما البنية العاملية للمناخ المدرسي لدى عينة الدراسة المختارة والتي يمثل افر ادها طلاب المرحلة الثانوية ؟ 
التعرف على البناء العاملي للمناخ المدرسي لدى عينة الدر اسة المختارة

\section{التعريف الاجرائي للمصطلحات}

من خلال اطلاع الباحثة على الدر اسات والابحاث السابقة و الكتابات النظرية امكن التوصل الى تحديد مفهوم المناخ المدرسي على النحو الآتي:

مجموعة من المعايير و القيم التي تدعم شعور الطلاب نفسيا و اجتماعيا وامنيا كنتاج للعلاقات الثخصية بين الطلبة واولياء الامور و المعلمين من خلال رؤية مشتركة للاحتر ام والالنزام عبر النظام التحليمي

\section{عينة البحث}

تكونت عينة البحث من . . طالب وطالبة تم اختيار هم طلبة المرحلة

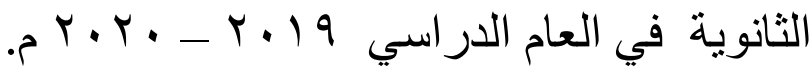
ادوات البحث مقياس المناخ المدرسي:

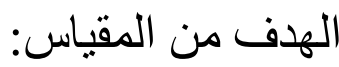

قياس المناخ كما يتمثل فيمجموعة من المعايير والقيم التي تدعم شعور الطلاب نفسيا واجتماعيا وامنيا كنتاج للعلاقات الشخصية بين الطلبة واولياء الامور و المعلمين من خلال رؤية مشتركة للاحتر ام والالتز ام عبر النظام التعلبيمي 

خطوات إعداد المقياس: خطو ات إعداد المقياس:

الاطلاع على التعريفات المحدة لمفهوم المناخ المدرسي، والاطلاع على الدر اسات و الأبحاث السابقة ذات العلاقة.

الاستفادة من بعض المقاييس المعدة لقياس المناخ المدرسي. وكان من نتيجة هذه الخطوة:

$$
\text { ـ ـ تحديد مفهوم المناخ المدرسي. }
$$

\section{إعداد مقياس المناخ المدرسي في صورته الأولية.}

- بلغت عبار ات المقياس VT عبارة تم اعدادها في صورة تقرير ذاتي يجيب عليها الطالب في ظل ثلاثة اختيار ات (دائما - أحيانا ـ أبدا). الخصائص السيكو مترية

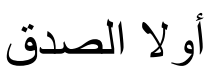
صدق المفردات

تم حساب معامل الارنباط بين درجة العبارة ودرجة البعد الذي نتنمي إليه لمقياس المناخ المدرسي ،وذلك بعد تطبيق المقياس على العينة الاستطلاعية والتي بلغ عدد أفر ادها ( . () طالبا وطالبة من نفس المجتمع الأصلي لعينة الدر اسة ، و الجدول التالي يوضح ذلك. 
معاملات الارتباط بين درجة العبارة ودرجة البعد الأي تنتمي إليه لمقياس المناخ المدرسي(ن $(1 \cdots=$

\begin{tabular}{|c|c|c|c|c|c|c|c|c|c|}
\hline \multicolumn{2}{|c|}{ احترام الأت } & \multicolumn{2}{|c|}{ الأمان المدرسي } & \multicolumn{2}{|c|}{ بعضهم البعض دعل } & \multicolumn{2}{|c|}{ فرص الذكم } & \multicolumn{2}{|c|}{ دعم المعلمين } \\
\hline معامل & رقم & معامل & رقم & معامل & رقم & معامل & رقم & معامل & رقم \\
\hline الارتباط & العبارة & الارتباط & العبارة & الارتباط & العبارة & الارتباط & العبارة & الارتباط & العبارة \\
\hline $0.539^{* * *}$ & 29 & $0.617^{* * *}$ & 21 & $0.611^{* * *}$ & 13 & $0.608^{* * *}$ & 8 & $0.566^{* *}$ & 1 \\
\hline $0.715^{* * *}$ & 30 & $0.545^{* * *}$ & 22 & $0.712^{* *}$ & 14 & $0.502^{* * *}$ & 9 & $0.645^{* *}$ & 2 \\
\hline 0.015 & 31 & $0.670^{* * *}$ & 23 & $0.766^{* * *}$ & 15 & $0.513^{* * *}$ & 10 & $0.516^{* * *}$ & 3 \\
\hline $0.565^{* * *}$ & 32 & $0.533^{* * *}$ & 24 & $0.5^{90^{* *}}$ & 16 & $0.599^{* * *}$ & 11 & $0.599^{* *}$ & 4 \\
\hline $0.596^{* * *}$ & 33 & $0.526^{* * *}$ & 25 & $0.587^{* * *}$ & 17 & $0.677^{* * *}$ & 12 & $0.611^{* * *}$ & 5 \\
\hline $0.661^{* * *}$ & 34 & $0.655^{* *}$ & 26 & $0^{2.573} 3^{* *}$ & 18 & & & $0.701^{* * *}$ & 6 \\
\hline $0.527^{* * *}$ & 35 & $0.715^{* *}$ & 27 & $0.597^{* *}$ & 19 & & & $0.598^{* *}$ & 7 \\
\hline $0.713^{* * *}$ & 36 & $0.656^{* * *}$ & 28 & $0.558^{* * *}$ & 20 & & & & \\
\hline 0.026 & 37 & & & & & & ي & عi & \\
\hline
\end{tabular}

\section{يتضح من الجدول السابق ما يلي :}

أن معاملات الارتباط بين درجة العبارة ودرجة البُعد الذي تتتمي إليه دالة إحصائيا عند مستوى I ل. احتر ام الذات ، لذا تم حذفها من المقياس ؛ مما يشير إلى صدق المقياس. كما تم حساب معامل الارتباط بين درجة البُعد والدرجة الكلية للمقياس ، و الجدول التالي يوضح ذلك 
البنية العاملية للمناخ المدرسي لدى طلاب المرحة الثانوية

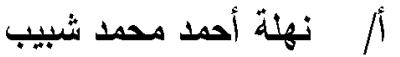

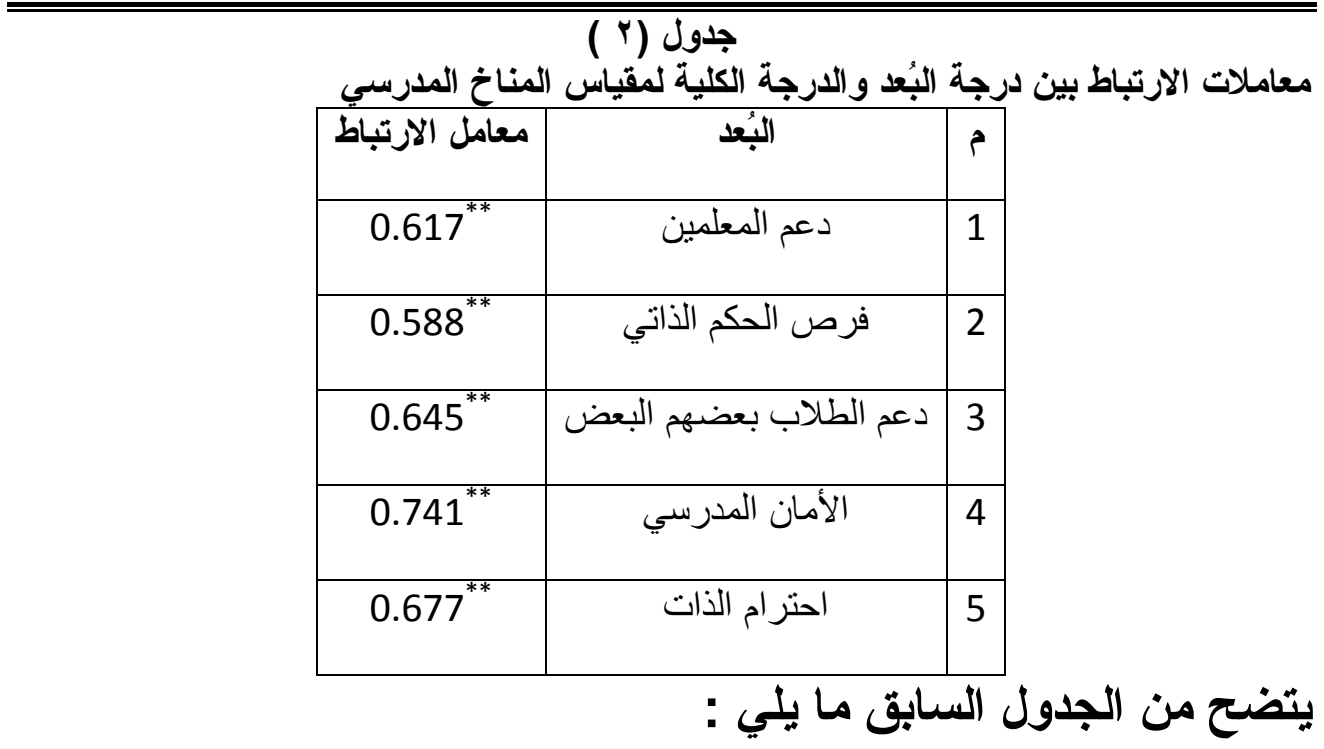

أن معاملات الارتباط بين درجة البُعد والدرجة الكلية لمقياس المناخ المدرسي

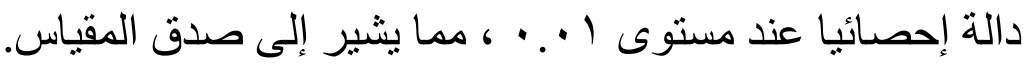
ثانيا : الثبات

تم حساب ثبات المقياس باستخدام معامل ألفا كرونباخ ، وذللك بعد حذف العبار ات

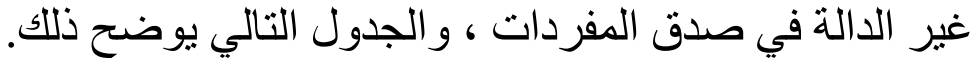

\section{جدول(r)}

معامل الثبات لأبعاد مقياس المناخ المدرسي والدرجة الكلية باستخدام معامل ألفا كرونباخ

\begin{tabular}{|c|c|c|}
\hline معامل الارتباط & 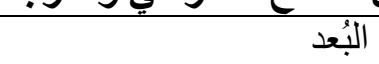 & م \\
\hline 0.736 & دعم المعلمين & 1 \\
\hline 0.716 & فرص الحكم الذاتي & 2 \\
\hline 0.706 & دعم الطلاب بعضهم البعض & 3 \\
\hline 0.746 & الأمان المدرسي & 4 \\
\hline 0.809 & احتر ام الذات & 5 \\
\hline 0.867 & الدرجة الكلية & 6 \\
\hline
\end{tabular}


أن معاملات الثبات لأبعاد مقياس المناخ المدرسي و الدرجة الكلية تراوحت

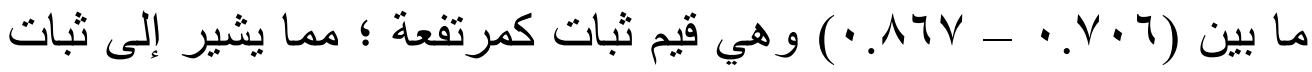
المقياس وإمكانية الوثوق في النتائج التي يمكن التوصل إليها من خلال تطبيق المقياس

\section{نتائج البحث:}

اعتمدت الباحثة على التحليل العاملى في الإجابة على تساؤل البحث لمعالجة البيانات إحصائياً . فقد توصلت نتائج التحليل العاملي إلى إلى تم التحقق من البنية العاملية للمقياس باستخدام التحليل العاملي ، وذلك بعد تطبيق المقياس في صورته الأولية على عينة استطلاعية بلغ عدد أفر ادها (9191) فردا يمثلون نفس أفر اد المجتمع الأصلي لعينة الدراسة ، و تم ذلك من خلال المصفوفة الارتباطية لدرجات أفراد العينة الاستطلاعية باستخدام طريقة التحليل العاملي. وتم استخدام طريقة المكونات الأساسية في حساب التحليل العاملي لمصفوفة معاملات الارتباط. وبعد التدوير المتعامد للعو امل بطريقة الفاريمكس Varimax ،وتم استخلاص خمسة عو امل كان الجذر الكامن لكل منها أكبر من الواحد ، و التشعبات الدالة على العو امل أكبر من r...، و الجدول التالي يوضح العوامل المستخرجة بعد التدوير المتعامد لمقياس المناخ المدرسي. 
البنية العاملية للمناخ المدرسي لدى طلاب المرحلة الثانوية

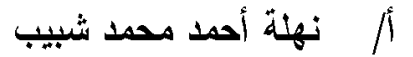

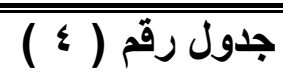

مصفوفة العوامل الناتجة من التحليل العاملي بعد التدوير المتعامد لمقياس المناخ المدرسي

\begin{tabular}{|c|c|c|c|c|c|c|c|c|c|c|c|}
\hline \multicolumn{5}{|c|}{ العوامل } & \multirow{2}{*}{ رقم العبارة } & \multicolumn{5}{|c|}{ العوامل } & \multirow{2}{*}{ رقب } \\
\hline الخامس & الرابع & الثالث & الثاني & الأول & & الخامس & الرابع & الثالث & الثاني & الأول & \\
\hline- & - & - & - & - & 21 & - & - & - & - & - & 1 \\
\hline & .354 & & & & 22 & & & & & .527 & 2 \\
\hline & .537 & & & & 23 & & & & & .444 & 3 \\
\hline & .360 & & & & 24 & & & & & .432 & 4 \\
\hline & .344 & & & & 25 & & & & & .437 & 5 \\
\hline & .399 & & & & 26 & & & & & .447 & 6 \\
\hline & .336 & & & & 27 & & & & & .393 & 7 \\
\hline - & - & - & - & - & 28 & & & & .351 & & 8 \\
\hline .451 & & & & & 29 & & & & .406 & & 9 \\
\hline .541 & & & & & 30 & & & & .423 & & 10 \\
\hline - & - & - & - & - & 31 & & & & .472 & & 11 \\
\hline .432 & & & & & 32 & & & & .503 & & 12 \\
\hline .408 & & & & & 33 & & & .496 & & & 13 \\
\hline .463 & . & & & & 34 & & & .511 & & & 14 \\
\hline - & - & - & - & - & 35 & & & .437 & & & 15 \\
\hline .387 & & & & & 36 & & & .543 & & & 16 \\
\hline - & - & - & - & - & 37 & - & - & - & - & - & 17 \\
\hline 1.641 & 1.810 & 1.942 & 2.556 & 4.746 & الجذر الكامن & & & .430 & & & 18 \\
\hline 4.69 & 5.17 & 5.55 & 7.30 & 13.56 & نسبة التباين & & & .305 & & & 19 \\
\hline 36.27 & 31.58 & 26.41 & 20.86 & 13.56 & نسبة التباين & & & .437 & & & 20 \\
\hline
\end{tabular}


أن التحليل العاملي لمقياس المناخ المدرسي أسفر عن خمسة عوامل كان

الجذر الكامن لكل منها على الترتيب (Y7

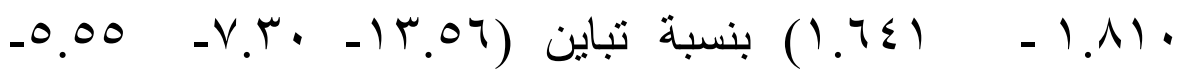

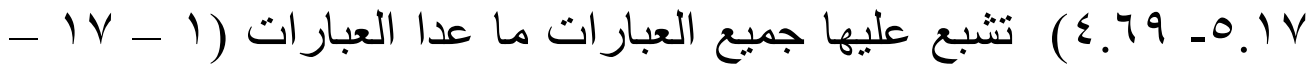

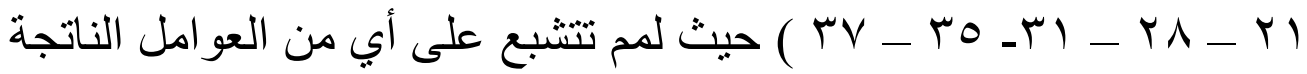
لذا تم حذفها من المقياس ، وفيما يلي عرض للعو امل الناتجة وتسمية كل عامل :

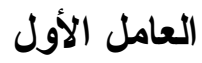

جدول ( 5 ) العبار ات التي تشبعت على العامل الأول

\begin{tabular}{|c|c|c|}
\hline 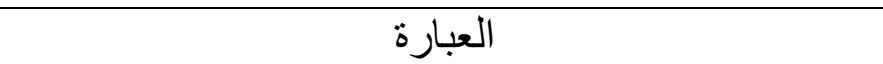 & 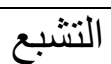 & 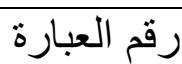 \\
\hline أساتذتي بهتمون بى . & .527 & 2 \\
\hline المعلمون يساعدون الطلاب الذين لديهم مشاكل بالمدرسة. & .444 & 3 \\
\hline يعمل أساتذتي بجد حتى أقوم بعمل جيد في الاختبار ات. & .432 & 4 \\
\hline أساتذتي يجعلوني اشعر بالرضا عن نفسى . & .437 & 5 \\
\hline يقدم المعلم لي ملاحظات تساعدنيفيمهامي الدر اسية. & .447 & 6 \\
\hline يصحح لي المعلم بعض الاخطاء التي اقع فيها اثناء & 393 & 7 \\
\hline & 4.746 & الجذر الكامن \\
\hline & 13.56 & نسبة التباين \\
\hline
\end{tabular}


بتضخح من الجدول السابق ما يلي :

أن العامل الأول تشبع به (6) عبار ات كان الجذر الكامن لها 4.746 بنسبة تباين 13.56\% وتكثف مضامين هذه العبار ات عن شعور الطالب باهتمام اساتذته ومساعدنهم له وأن المعلم يقدم له النصح و التوجيه و على هذا يمكن

تسمية هذا العامل بـ ( دعم المعلمين) .

العامل الثاني جدول ( 7 ) العبار ات التي تشبعت على العامل الثاني

\begin{tabular}{|c|c|c|}
\hline 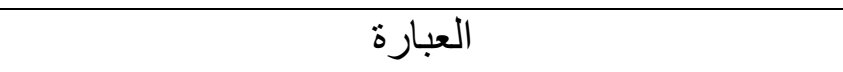 & التشبع & 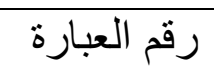 \\
\hline يعطى المعلم الطلاب الفرصة في تحديد بعض القواعد العن في المدرسة . & .351 & 8 \\
\hline الطلاب يساعدون في كيفية إدارة الوقت بالمدرسة & .406 & 9 \\
\hline يتم منح الطلاب الفرصة للمساعدة في اتخاذ القرار ات . & .423 & 10 \\
\hline 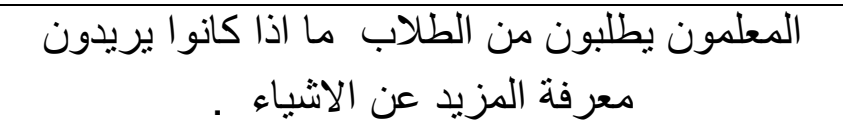 & .472 & 11 \\
\hline \multirow[t]{3}{*}{ أشعر بأنني ليس لدى الكثير لأفتخر به. } & .503 & 12 \\
\hline & 2.556 & 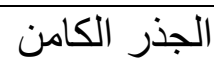 \\
\hline & 7.30 & 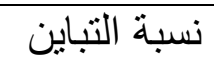 \\
\hline
\end{tabular}

يتضح من الجدول السابق ما يلي :

أن العامل الثاني تشبع به (0) عبارات كان الجذر الكامن لها

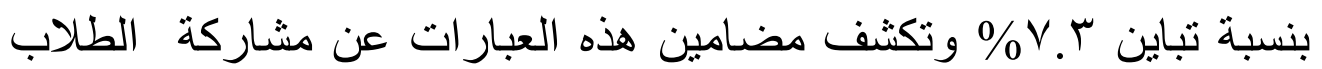


البنية العاملية للمناخ المدرسي لاثى طلاب المرحلة الثانوية

نهلة أحمد محمد شبيب لاب المبرح

في وضع القو اعد المنظمة للعمل داخل الفصل الدراسي مع منحهم الفرصة لأن بشاركو ا في اتخاذ القرارات الخاصة بهم مما بزيد من شعور هم بالفخر لما يمتلكونه من مهارات وعلى هذا يمكن تسمية هذا العامل بـ ( فرص

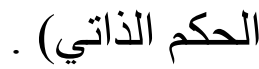

العامل الثالث

جدول ( 8 ) العبار ات التي تثبعت على العامل الثالث

\begin{tabular}{|c|c|c|}
\hline 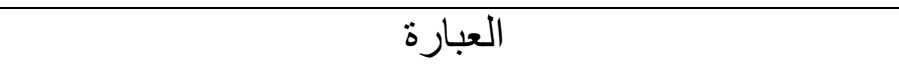 & التشبع & رقم العبارة \\
\hline يحترم الطلاب بعضهم البعض . & .496 & 13 \\
\hline يساعد الطلاب بعضهم البعض . & .511 & 14 \\
\hline يعطى الطلاب بعضهم البعض المثل في العمل الجماعي . & .437 & 15 \\
\hline الطلاب يزعجون بعضهم البعض في المدرسة & .543 & 16 \\
\hline الطلاب يثقون في بعضهم البعض . & .430 & 18 \\
\hline أثق في نصائح زملائيلي . & .305 & 19 \\
\hline يساعدني زملائي أثناء مو اجهة المشكلة. & .437 & 20 \\
\hline & 1.942 & 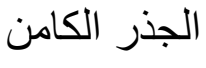 \\
\hline & 5.55 & نسبة التباين \\
\hline
\end{tabular}

يتضح من الجدول السابق ما يلي:

أن العامل الثالث نشبع به (V) عبار ات كان الجذر الكامن لها بـ9 ا أبسبة تباين 00.0\% وتكثف مضامين هذه العبار ات عن احتر ام الطلاب بعضهم البعض ومساعدة كل منهم للآخر في مواجهة مشكلاتهم مع ثقتهم في بعضهم 
البنية العاملية للمناخ المدرسي لدى طلاب المرحة الثانوية

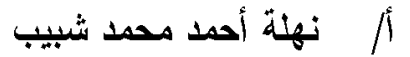

البعض و العمل معا بشكل جماعي ،و على هذا بمكن تسمية هذا العامل بـ

(دعم الطلاب بعضهم البعض) .

العامل الر ابع

جدول ( 9) العبارات التي تشبعت على العامل الرابع

\begin{tabular}{|c|c|c|}
\hline العبارة & التشبع & العبارة \\
\hline أفعل معظم الأشياء دون تركيز . & .354 & 22 \\
\hline اشعر بأنني أحتاج للبكاء كل يوم . & .537 & 23 \\
\hline لاى الكثير من الأصدقاء & .360 & 24 \\
\hline أثنعر بأنني وحيد في المدرسة . & .344 & 25 \\
\hline توجد أثنياء تز عجني معظم الوقت في المدرسة & .399 & 26 \\
\hline المدرسة مكان غير محبب لي . & .336 & 27 \\
\hline & 1.810 & الجامن \\
\hline & 5.17 & نسبة التباين \\
\hline
\end{tabular}

يتضح من الجدول السابق ما يلي :

أن العامل الرابع نشبع به (7) عبارات كان الجذر الكامن لها • (1. I.

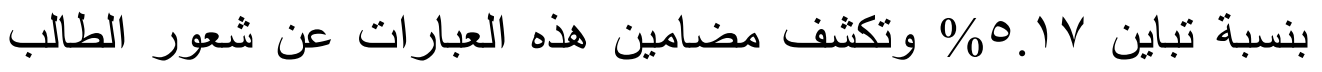


البنية العاملية للمناخ المدرسي لاثى طلاب المرحلة الثانوية

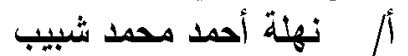

بالراحة والاستقرار داخل المدرسة ورغبته في أن يتواجد بها مع تكوين

صداقات عديدة تجعله يستمتع بالعمل المدرسي ،و على هذا يمكن تسمية هذا

$$
\text { العامل بـ (الأمان المدرسي). }
$$

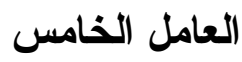

جدول (10) العبار ات التي تشبعت على العامل الخامس

\begin{tabular}{|c|c|c|}
\hline 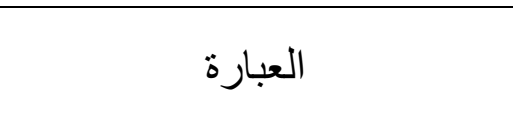 & التشبع & العبارة \\
\hline أنا راضي عن نفسى . & .451 & 29 \\
\hline أعتقد أننى لست جيد . & .541 & 30 \\
\hline أشتعر بأنني غير محدد الأهداف . & .408 & 33 \\
\hline أشنعر بأنني جيد مثل غيرى . & .463 & 34 \\
\hline أَثُعر بالفخر بمستو اي الدر اسي . & .387 & 36 \\
\hline & 1.641 & الكامن \\
\hline & 4.69 & التباين \\
\hline
\end{tabular}

يتضح من الجدول السابق ما يلي:

أن العامل الخامس تشبع به (0) عبار ات كان الجذر الكامن لها ــ (آ. أبنسبة

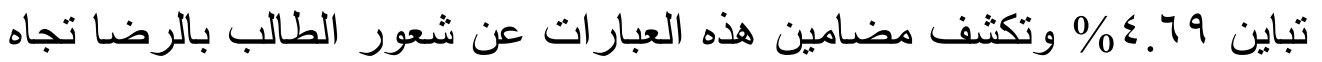

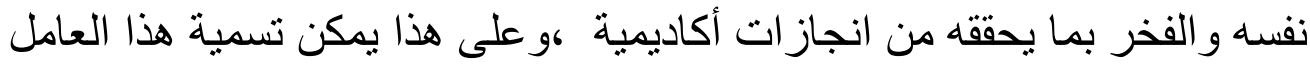

$$
\text { بـ (احتر ام الذات). }
$$


البنية العاملية للمناخ المدرسي لدى طلاب المرحلة الثانوية

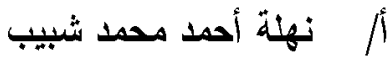

مفهوم المناخ المدرسي في البيئة المصريةة :

في ضوء ما أسفرت عنه نتائج التحليل العاملي من نتائج لدى أفراد العينة المختارة، فقد تم التوصل إلى تحديد مفهوم المناخ المدرسي على النحو الآتي

مجمو عة من المعايير و القيم التي تدعم شعور الطلاب نفسيا و اجتماعيا وامنيا كنتاج للعلاقات الثخصية بين الطلبة واولياء الامور و المعلمين من خلال رؤية مشتركة للاحتر ام و الالتز ام عبر النظام التعليمي. 
Dary, Teri, \& Pickeral, Terry. (2013). School climate: Practices for implementation and sustainability. A school climate practice brief(1).

Freiberg, H. J. (1998). Measuring school climate: Let me count the ways. Educational Leadership, 56(1), 22-26.

Freiberg, H.J. \&Stein, T.A. (1999).School Climate: Measuring, improving and sustaining healthy learning environments. New York: Routledge Falmer

Haynes, Norris M, Emmons, Christine L, Gebreyesus, Sara, \& Ben-Avie, Michael. (1996). The school development program evaluation process. Rallying the whole village: The Comer process for reforming education, 123-146.

Johnson, William L, \& Johnson, Annabel M. (1993). Validity of the quality of school life scale: A primary and second-order factor analysis. Educational and Psychological Measurement, 53(1), 145-153.

Kuperminc, G. P., Leadbeater, B. J., \& Blatt, S. J. (2001). School social climate and individual differences in vulnerability to psychopathology among middle school students. Journal of School Psychology, 39(2), 141-159.

Lindahl, R. A. (2011). The crucial role of assessing the school's climate and culture in planning for school improvement. Educational Planning, 20(1), 16-30. 
البنية العاملية للمناخ المدرسي لدى طلاب المرطة الثانوية

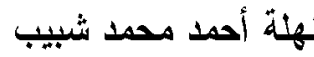

MacNeil, Angus J, Prater, Doris L, \& Busch, Steve. (2009).

The effects of school culture and climate on student achievement. International Journal of Leadership in Education, 12(1), 73-84.

National School Climate Council. (2007). The School Climate Challenge: Narrowing the gap between school climate research and school climate policy, practice guidelines and teacher education policy. New York: Center for Social and Emotional Education; \& Denver, CO: National Center for Learning and Citizenship, Education Commission of the States. Available:

http://csee.net/climate/aboutcsee/school_climate_chal lenge.pdf.

Taylor, D. L., \& Tashakkori, A. (1995). Decision participation and school climate as predictors of job satisfaction and teacher's sense of efficacy. Journal of Experimental Education, 63(3), 217-227.

Yueming Jia, Y. M., Way, N., Ling, G. M., Yoshikawa, H., Chen, X. Y., Hughes, D., \& Lu, Z. (2009). The influence of student perceptions of school climate on socioemotional and academic adjustment: A comparison of Chinese and American adolescents. Child Development, 80, 1514-1530. 